\title{
IL-1 drives breast cancer growth and bone metastasis in vivo
}

\author{
Ingunn Holen ${ }^{1}$, Diane V. Lefley ${ }^{1}$, Sheila E. Francis ${ }^{2}$, Sarah Rennicks ${ }^{1}$, Steven \\ Bradbury ${ }^{1}$, Robert E. Coleman ${ }^{1}$, Penelope Ottewell ${ }^{1}$ \\ ${ }^{1}$ Academic Unit of Clinical Oncology, Department of Oncology and Metabolism, Mellanby Centre for Bone Research, University \\ of Sheffield, Sheffield S10 2RX, UK \\ ${ }^{2}$ Department of Infection Immunity and Cardiovascular Disease, University of Sheffield, Sheffield S10 2RX, UK \\ Correspondence to: Penelope Ottewell, email: P.D.Ottewell@sheffield.ac.uk
}

Keywords: breast cancer, bone metastasis, IL-1B, IL-1R, anakinra

Received: June 01, 2016

Accepted: September 15, 2016

Published: September 27, 2016

\section{ABSTRACT}

Background: We have recently identified interleukin 1B (IL-1B) as a potential biomarker for predicting breast cancer patients at increased risk for developing bone metastasis. In mouse models, IL-1B and its receptor (IL-1R1) are upregulated in breast cancer cells that metastasise to bone compared with cells that do not. We have now investigated the functional role of IL-1 by blocking IL-1R signalling with the clinically licensed antagonist, anakinra.

Methodology: 6-week old female BALB/c mice received a subcutaneous or intravenous injection of MDA-MB-231-IV or MCF7 cells. Anakinra $(1 \mathrm{mg} / \mathrm{kg} / \mathrm{day})$ or placebo was administered 3 days before (preventative) or 7 days later (treatment). Tumour volume, apoptosis (TUNEL, Caspase 3), proliferation (Ki67) and angiogenesis (CD34, VEGF and endothelin) were analysed. Effects on bone were measured by UCT, and TRAP, P1NP, IL-1B, TNF alpha and IL-6 ELISA.

Results: Anakinra significantly reduced growth of MDA-MB-231-IV tumours in bone from $6.50+/ 3.00 \mathrm{~mm}^{2}$ (placebo) to $2.56+/-1.07 \mathrm{~mm}^{2}$ (treatment) and $0.63+/-$ $0.18 \mathrm{~mm}^{2}$ (preventative). Anakinra also reduced the number of mice that developed bone metastasis from $90 \%$ (placebo) to $40 \%$ (treatment) and $10 \%$ (preventative). Anti-tumour effects were not confined to bone, subcutaneous tumour volumes reduced from $656.68 \mathrm{~mm}^{3}$ (placebo) to $160.47 \mathrm{~mm}^{3}$ (treatment) and $31.08 \mathrm{~mm}^{3}$ (preventative). Anakinra did not increase tumour cell apoptosis but reduced proliferation and angiogenesis in addition to exerting significant effects on the tumour environment reducing bone turnover markers, IL-1B and TNF alpha.

Conclusions: Our novel data demonstrate a functional role of IL-1 signalling in breast tumour progression and metastasis, supporting that anakinra could be repurposed for the treatment of breast cancer bone metastasis.

\section{INTRODUCTION}

About three quarters of patients that develop metastatic breast cancer will have bone involvement. Metastatic bone disease is incurable with a median survival of $\sim 2-3$ years following diagnosis, hence new therapeutic approaches are still needed to improve outcome in this poor prognosis group. We have recently identified IL-1B as a potential prognostic biomarker for early breast cancer patients at increased risk for the subsequent development of skeletal metastases [1]. In a study of 150 patients presenting with stage II /III breast cancer included in a clinical trial (AZURE), we found significant correlations between expression of IL-1B in the primary tumour and both disease recurrence at any site $(\mathrm{P}<0.0001)$ and, specifically, metastasis to bone $(\mathrm{P}<0.0001)$ after median follow up of 84 months. Furthermore, mouse model systems of human breast cancer have provided evidence that increased IL-1B expression is linked with the ability of tumour cells to home to the bone environment [1].

IL-1B expression is elevated in a variety of cancers (including breast, prostate, colon, lung, head and neck cancers and melanomas) and patients with IL-1B producing tumours generally have a worse prognosis [2]. Whereas 
IL-1B expression has been implicated in metastatic behaviour of breast cancer cells in vitro [3-6], no functional in vivo studies have been published and no specific link to bone metastasis has been explored. The most compelling evidence for a role of IL-1B in bone metastasis was reported using a mouse model of prostate cancer. In this study, overexpression of IL-1B in non-metastatic prostate cancer cells promoted bone metastasis, whereas knockdown of IL-1B impaired bone progression by metastatic cells [7]. Experimental models of Lewis lung carcinoma, pulmonary adenocarcinoma and squamous adenocarcinoma have shown that local production of IL-1B influences tumour growth and metastasis, either through direct proliferative effects or by promoting inflammatory and angiogenic pathways in surrounding host cells [5, 8-9]. Evidence from giant cell tumour and glioma cells, small cell lung cancer and melanoma indicate that IL$1 \mathrm{~B}$ induces proliferation of new blood vessels in vivo and that these activities are mediated indirectly via IL-1B effects on other cell types, including fibroblasts and immune cells in the tumour microenvironment [10-11]. It is likely that IL1B directly impacts on tumour aggressiveness and metastatic potential due to its ability to influence multiple molecular pathways, and that blocking IL-1B activity therefore has the potential to be an effective anti-cancer therapy.

IL-1B exerts its activity by binding to the type 1 receptor (IL-1R1) and clinical data from patients with prostate cancer show an association between high levels of IL-1R1 in the primary tumour with poor prognosis, while low levels of IL-1B in the primary tumour and associated stroma predict a good prognosis [12]. Anakinra, a recombinant IL-1 receptor antagonist that binds to IL-1 receptors type I and type II, is currently licenced to treat patients with neonatal onset multi system inflammatory disease and rheumatoid arthritis, and has also recently been used in a Phase 2 clinical trial in patients with myocardial infarction $(100 \mathrm{mg} /$ day for 14 days) [13-15]. Trials in over 250,000 patients have shown anakinra to have an excellent safety profile, being well tolerated by patients who report little to no side effects and is not associated with increased susceptibility to opportunistic infections compared with other biological agents [16]. In the current study, bone homing MDA-MB-231 IV cells were injected into the lateral tail vein to model bone metastasis [1] and MDA-MB-231-IV and MCF7 cells were injected subcutaneously to model non-metastatic oestrogen receptor (ER) +ve and ER-ve breast cancer. These models were used to investigate the therapeutic efficacy of a clinically relevant dose of anakinra $(1 \mathrm{mg} / \mathrm{kg} /$ day, equivalent to $100 \mathrm{mg} /$ day in people [17]) to explore the potential use as a novel treatment for breast cancer bone metastasis.

\section{RESULTS}

\section{Effects of IL-1R blockade on tumour growth in bone}

To investigate the role of IL-1 on breast cancer growth in bone we used two protocols outlined in
Figure 1A: 1) A preventative protocol, in which 1mg/ $\mathrm{kg}$ anakinra was injected every $24 \mathrm{~h}$ for 31 days starting 3 -days before injection of tumour cells to determine whether blocking IL-1R modified tumour cell homing and colonisation of bone; 2) a treatment protocol, in which $1 \mathrm{mg} / \mathrm{kg}$ anakinra was injected every $24 \mathrm{~h}$ for 21 days, starting 7 days after injection of tumour cells, to assess the effects on progression of established tumours. Pretreatment with anakinra for 3-days had no effect on the numbers of disseminated tumour cells in bone (Figure 1b). Two-photon analysis showed similar numbers of DiDlabelled tumour cells present in the proximal tibiae of mice administered placebo or anakinra (treatment protocol or preventative protocol) 28 days following injection of tumour cells.

Daily injection of anakinra resulted in significantly fewer mice having detectable tumours in the long bones 28 days following injection of MDA-MB-231-IV cells (Figure 1c): Tumours were detectable in long bones of $80 \%$ of placebo treated mice, $38 \%$ of mice in the treatment group and $18 \%$ of mice in the preventative group $(\mathrm{P}=0.04$ and $\mathrm{P}=0.01$ compared with placebo for treatment and preventative, respectively) (Figure 1c). Administration of anakinra not only reduced numbers of mice with detectable tumours but also decreased tumour load. Tumour area was reduced by $62 \%$ in mice receiving anakinra using the treatment protocol and $91 \%$ in mice receiving the preventative protocol group $(\mathrm{P}>0.001$ and $\mathrm{P}>0.0001$ compared with placebo for treatment and preventative, respectively, $\mathrm{n}=16$ mice/group) (Figure 1d). Interestingly, administration of anakinra did not affect the time to detection of tumour in bones (Figure 1e); the first tumours were detected on day 19 in placebo treated mice, day 16 in mice administered anakinra under the treatment protocol and day 22 under the preventative protocol. These results suggest that blocking IL-1R signalling did not delay development of metastases from disseminated tumour cells, but decreased their capability to progress to overt metastatic tumours and/or the rate at which these tumours grew.

Histological analysis of tumours in bone showed no statistical differences in numbers of TUNEL positive cells per $\mathrm{mm}^{2}$ of tumour between mice administered placebo those that received anakinra. However, tumours in bones from mice treated with the preventative anakinra protocol had significantly lower numbers of TUNEL positive cells $\left(189+/-8.1\right.$ cells per $\mathrm{mm}^{2}$ of viable tumour) compared with tumours from mice receiving the treatment protocol $\left(673+/-52\right.$ cells per $\mathrm{mm}^{2}$ of viable tumour) ( $\mathrm{P}=0.02)$ (Figure $2 \mathrm{a})$. These data suggest that reduced tumour growth in the anakinra treated mice was not caused by increased levels of apoptotic tumour cell death. Administration of anakinra did have significant effects on tumour cell proliferation (Figure 2b) and angiogenesis (Figure 2c). Numbers of Ki67 positive tumour cells reduced by $85 \%$ in mice receiving anakinra via the treatment protocol and $73 \%$ in mice administered 
a) Start treatment Inject MDA-MB-231-IV

Sacrifice

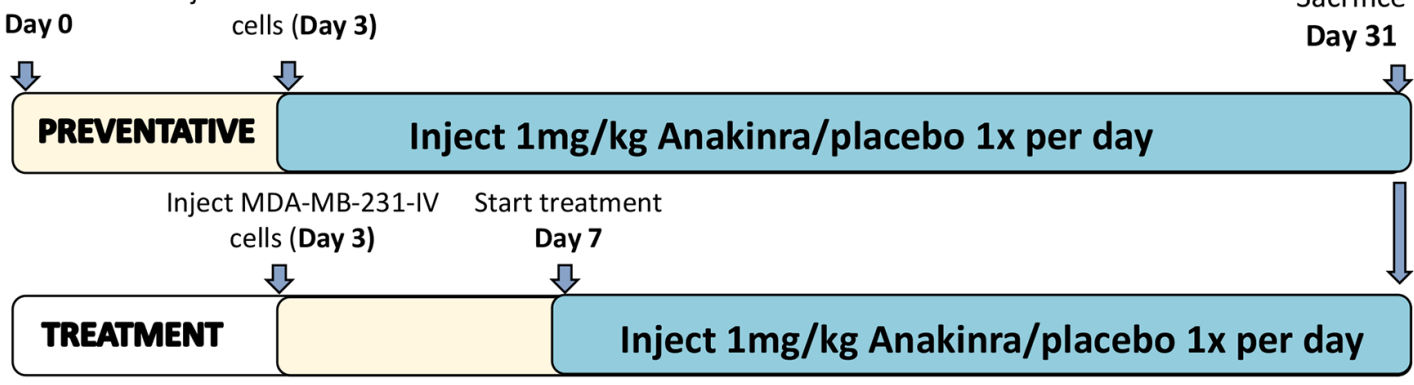
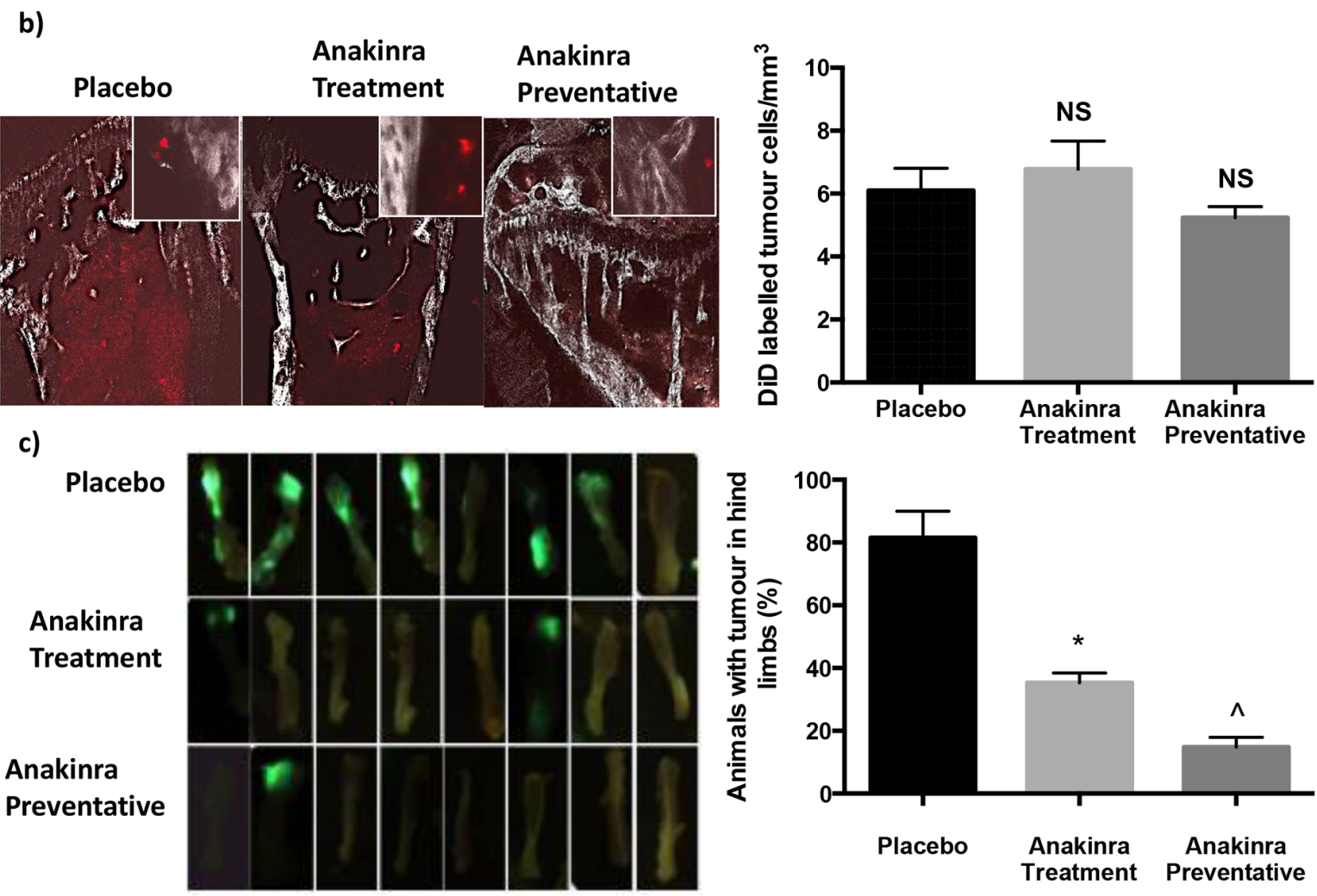

d)

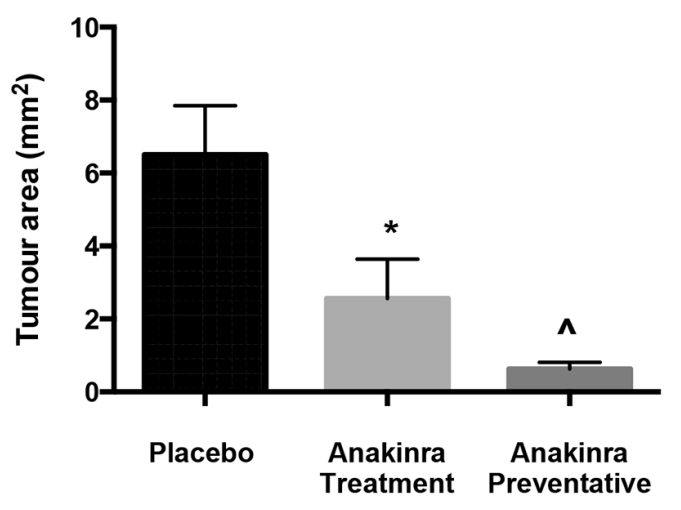

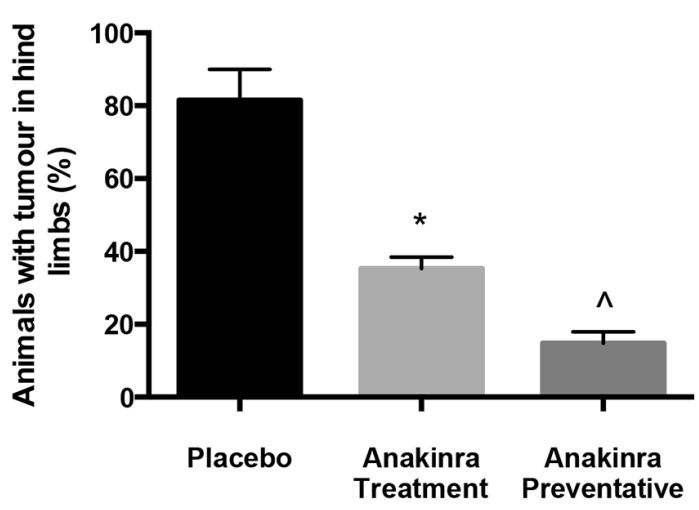

e)
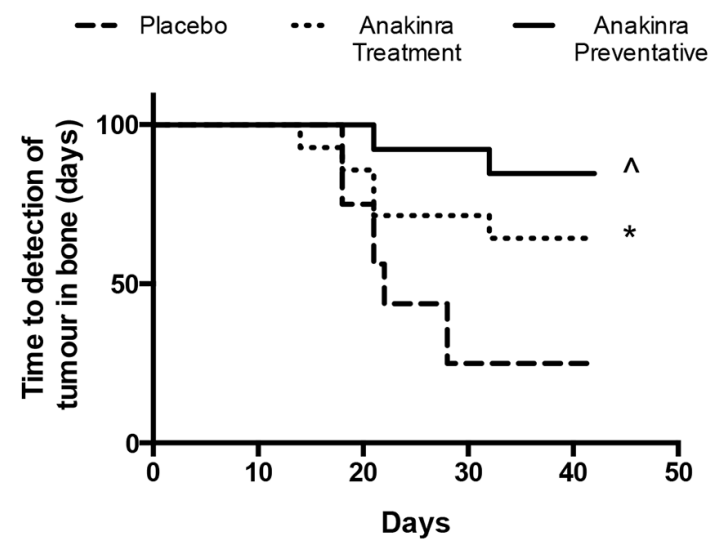

Figure 1: Effects of anakinra on MDA-MB-231 breast cancer dissemination and growth in bone. 6-week old BALB/c nude mice were administered $1 \mathrm{mg} / \mathrm{kg}$ /day anakinra 3-days before or 7 days after intra-venous injection of MDA-MB-231-IV cells and culled 28 days after tumour cell injection. Protocol outline shown in a. b. Shows the number +/- SEM and photomicrographs of DiD labelled, nonproliferating, tumour cells in the trabecular area of the tibia. c. Shows mean $+/$ - SEM from two separate experiments ( $\mathrm{n}=8 \mathrm{mice} / \mathrm{experiment})$ percentage of mice with tumours in their hind limbs on day 28 and ex vivo photographs of GFP expressing tumours in the left tibiae of mice from experiment 2. Mean tumour area $+/$ - SEM and time until detection of tumour growth in bone are shown in panels $\mathrm{d}$ and $\mathrm{e} . *=\mathrm{p}<0.01$ compared with placebo, $\wedge=\mathrm{P}<0.01$ compared with placebo or treatment protocol. 
a)

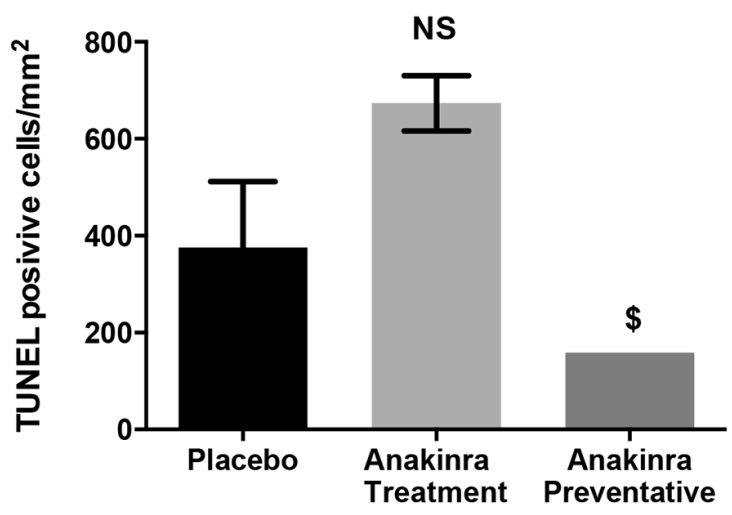

b)

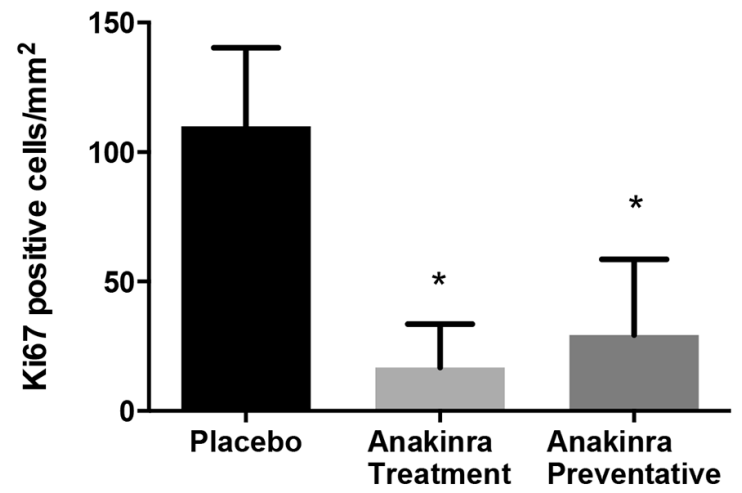

c)
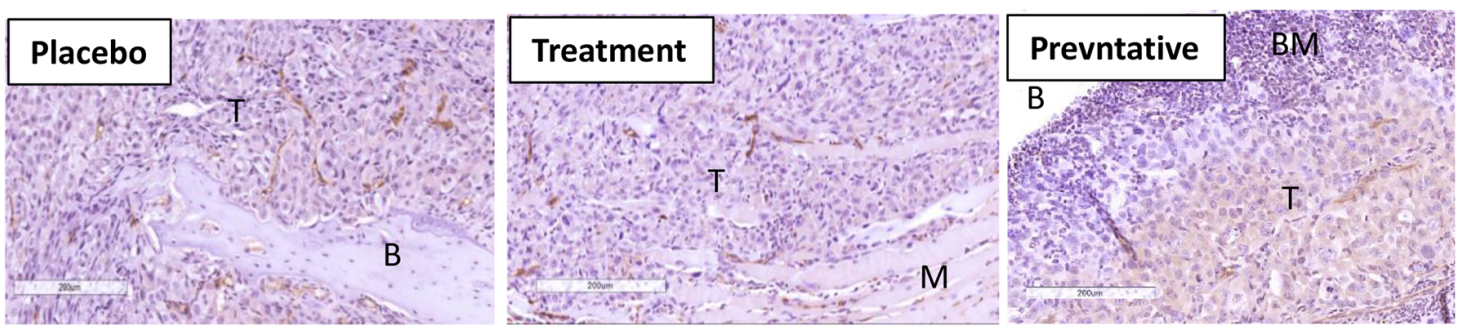

d)
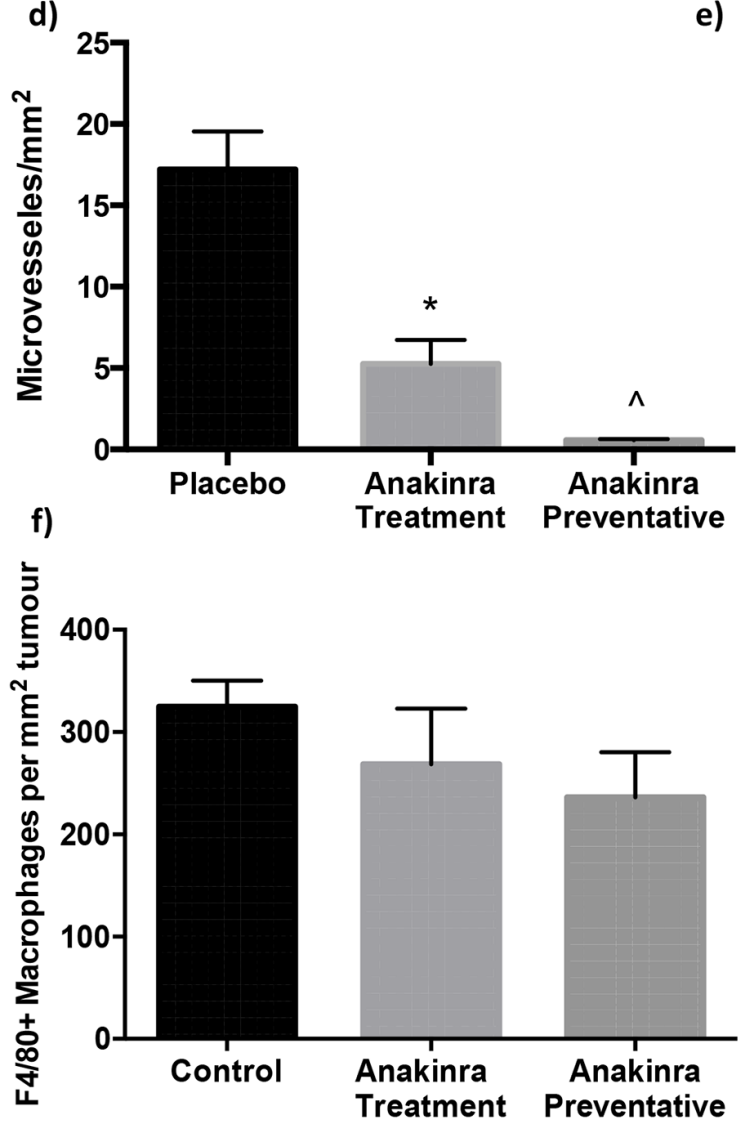

e)
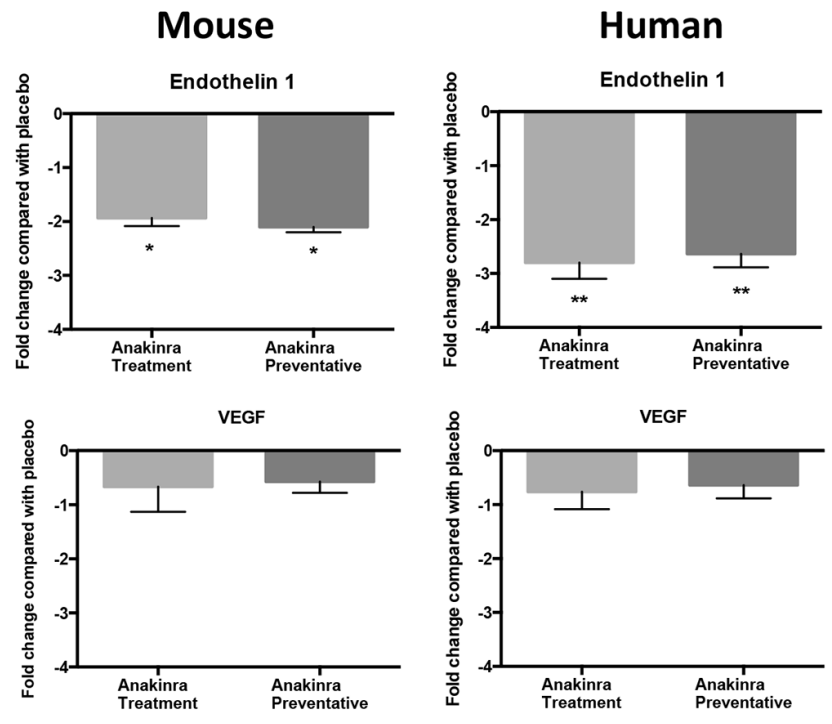

Figure 2: Effects of anakinra on viability of MDA-MB-231-IV tumours in bone. Numbers of tumour cells undergoing apoptosis per $\mathrm{mm}^{2}$ tumour (+/- SEM) were analysed following in situ hybridisation using a TUNEL kit a. and numbers of actively proliferating cells per $\mathrm{mm}^{2}$ (+/- SEM) were assessed following Ki67 staining b. Photomicrographs show CD34 staining of endothelial cells in MDA-MB-231IV tumours (T) in bone (B) 25 days after tumour cell injection c. numbers of CD34 positive blood vessels per $\mathrm{mm}^{2}$ of tumour are shown in (c) and d. shows Endothelin 1 and VEGF gene expression in mouse bone and human MDA-MB-231-IV tumours growing in mouse bone following daily injection with anakinra compared with placebo. Panel f. shows numbers of F4/80+ve macrophages per $\mathrm{mm}^{2}$ of tumour. $*=$ $\mathrm{p}<0.01$ compared with placebo, ${ }^{\wedge}=\mathrm{P}<0.01$ compared with placebo or treatment protocol. 
the preventative protocol, compared with placebo (P $>0.01$ for treatment and preventative compared with placebo). Anakinra also significantly reduced the number of micro vessels in MDA-MB-231-IV bone tumours by $62 \%$ (treatment protocol) and 87\% (preventative protocol), $(\mathrm{P}<0.001$ compared with placebo; Figure $2 \mathrm{~d})$. The antivascular effects of anakinra observed on histological sections were confirmed by gene expression analysis of Endothelin 1 and VEGF in tumours isolated from mouse tibiae. Both mouse and human Endothelin 1 mRNA levels was decreased 2 fold and 2.8 fold respectively following administration of anakinra via the treatment or preventative protocols compared with placebo $(\mathrm{P}<$ 0.01 ; Figure 2e). Repeated administration of a higher dose of anakinra, $10 \mathrm{mg} / \mathrm{kg}$, have previously been shown to increase macrophage infiltration into tumours [24]. In our current study $1 \mathrm{mg} / \mathrm{kg} /$ day anakinra did not affect macrophage infiltration into tumours within bone (Figure 2f). Numbers of F480+ve cells reduced from $325.2 \pm 25.17$ per $\mathrm{mm}^{2}$ of tumour in the placebo group to $268.6 \pm 54.39$ per $\mathrm{mm}^{2}$ in the treatment group and $235.9 \pm 44.00$ per $\mathrm{mm}$ in the preventative group, no significant differences were recorded. Taken together, these data indicate that blocking IL-1R signalling does not kill tumour cells via apoptosis, but reduces the growth of tumours in bone via decreasing tumour cell proliferation and neo-vascularisation.

\section{Effects of anakinra on the bone microenvironment}

We first investigated the effects of blocking IL-1R activity with a single $1 \mathrm{mg} / \mathrm{kg}$ dose of anakinra on bone turnover and pro-inflammatory cytokines in bone marrow of BALB/c mice over a $24 \mathrm{~h}$ time period (Figure 3). ELISA analysis shows a $41 \%$ drop in osteoclast (TRAP) activity over the first 4 hours $(\mathrm{P}=0.02)$, osteoclast activity partially recovered over the next 20 hours to $6.10+/-0.17$ $\mathrm{U} / \mathrm{L}$ but remained $17 \%$ lower than the baseline recording of $7.33+/-0.52 \mathrm{U} / \mathrm{L}$. Decreased osteoclast activity was mirrored by a decrease in osteoblast activity. P1NP concentrations decreased from $239.67+/-21.40$ at baseline to 168.67 at 4 hours $(P=0.04)$. Similarly to osteoclasts, osteoblast activity partially recovered by $24 \mathrm{~h}$ to $209.66+/$ 11.26 and although this remained $13 \%$ below the baseline levels there was no significant difference between P1NP concentrations at baseline and $24 \mathrm{~h}$ following treatment (Figure 3a).

We next investigated whether blocking activity of IL-1R affected the secretion of pro-inflammatory cytokines into the bone marrow (Figure 3b). A single injection of anakinra resulted in decreased concentrations of IL-1B by $50 \%$, from $1.162+/-0.04 \mathrm{pg} / \mathrm{ng}$ protein at baseline to 0.69 $+/-0.15 \mathrm{pg} / \mathrm{ng}$ protein $4 \mathrm{~h}$ post injection and $0.54+/-0.05$ $\mathrm{pg} / \mathrm{ng}$ protein $24 \mathrm{~h}$ after injection $(\mathrm{P}<0.01$ and $\mathrm{P}<0.001$ compared with $0 \mathrm{~h}$, respectively). Concentrations of TNF alpha also decreased by $80 \%$ from $1.67+/-0.12 \mathrm{pg} / \mathrm{ng}$ protein at baseline to $0.35+/-0.34 \mathrm{pg} / \mathrm{ng}$ protein $4 \mathrm{~h}$ after injection, however, TNF alpha levels returned to baseline, $24 \mathrm{~h}$ post injection with anakinra. Concentrations of IL-6 in the bone marrow of 6 -week old BALB/c mice were low and did not change following administration of anakinra (data not shown).

To assess the effects of continuous treatment with $1 \mathrm{mg} / \mathrm{kg} /$ day anakinra on pro-inflammatory cytokines in immunocompromised mice used in the tumour studies, bone marrow was taken from non-tumour bearing forelimbs and analysed $24 \mathrm{~h}$ after administration of the last treatment (Figure 3c). Administration of anakinra for 24 days (treatment) or 31 days (preventative) reduced IL-1B from $1.36 \pm 0.17 \mathrm{pg} / \mathrm{ng}$ of total protein (placebo) to 0.52 $\pm 0.13 \mathrm{pg} / \mathrm{ng}(\mathrm{P}<0.01)$ and $0.47 \pm 0.09 \mathrm{pg} / \mathrm{ng}$ of protein respectively $(\mathrm{P}<0.01)$. TNF $\alpha$ was also reduced from 1.60 $\pm 0.26 \mathrm{pg} / \mathrm{ng}$ of total protein in bone marrow from mice administered placebo to $0.95 \pm 0.21 \mathrm{pg} / \mathrm{ng}$ protein in mice administered anakinra for 24 days $(\mathrm{P}<0.01)$ and to $0.73 \pm 0.13 \mathrm{pg} / \mathrm{ng}$ protein in mice administered anakinra for 31 days $(\mathrm{P}<0.001)$. These data indicate that daily administration of anakinra leads to a sustained reduction in IL-1B and TNF $\alpha$ concentrations and is therefore an appropriate treatment strategy for investigating the effects if IL-1 on tumour growth in bone.

Continued administration of anakinra for 21 days (in the treatment protocol) or for 31 days (in the preventative protocol) had no significant effect on trabecular bone volume in tumour-free tibiae (Figure $4 \mathrm{a}$ and $4 \mathrm{~b}$ ). In tumour bearing tibiae, administration of anakinra resulted in significantly increased bone volume: tissue volume (BV/TV) \% compared with bones from mice administered placebo $(\mathrm{P}<0.01$ for the treatment and $\mathrm{P}<0.001$ for the preventative protocol). Injection of anakinra using either protocol showed a trend towards deceased numbers of osteoclast/osteoblasts per $\mathrm{mm}$ of trabecular bone and decreased percentage of trabecular bone in the tibiae covered by these cells compared with placebo, however, these differences were not statistically significant (Figure 4c-4f).

\section{Effects of anakinra on subcutaneous MDA-MB- 231-IV and MCF7 tumours}

We next determined whether the anti-tumour effects of anakinra were restricted to ER-ve breast tumours growing in bone, or whether peripheral tumour growth could also be inhibited. For these experiments, ER-ve MDA-MB-231-IV or ER+ve MCF7 cells were injected subcutaneously and mice treated with anakinra according to the protocols outlined in Figure 1a. Administration of anakinra using the treatment protocol significantly decreased growth of subcutaneous MDA-MB-231-IV tumours from day $14(\mathrm{P}<0.001)$ and of MCF7 tumours from day 38 compared with placebo $(\mathrm{P}<0.0001)$, which was further reduced using the preventative protocol 

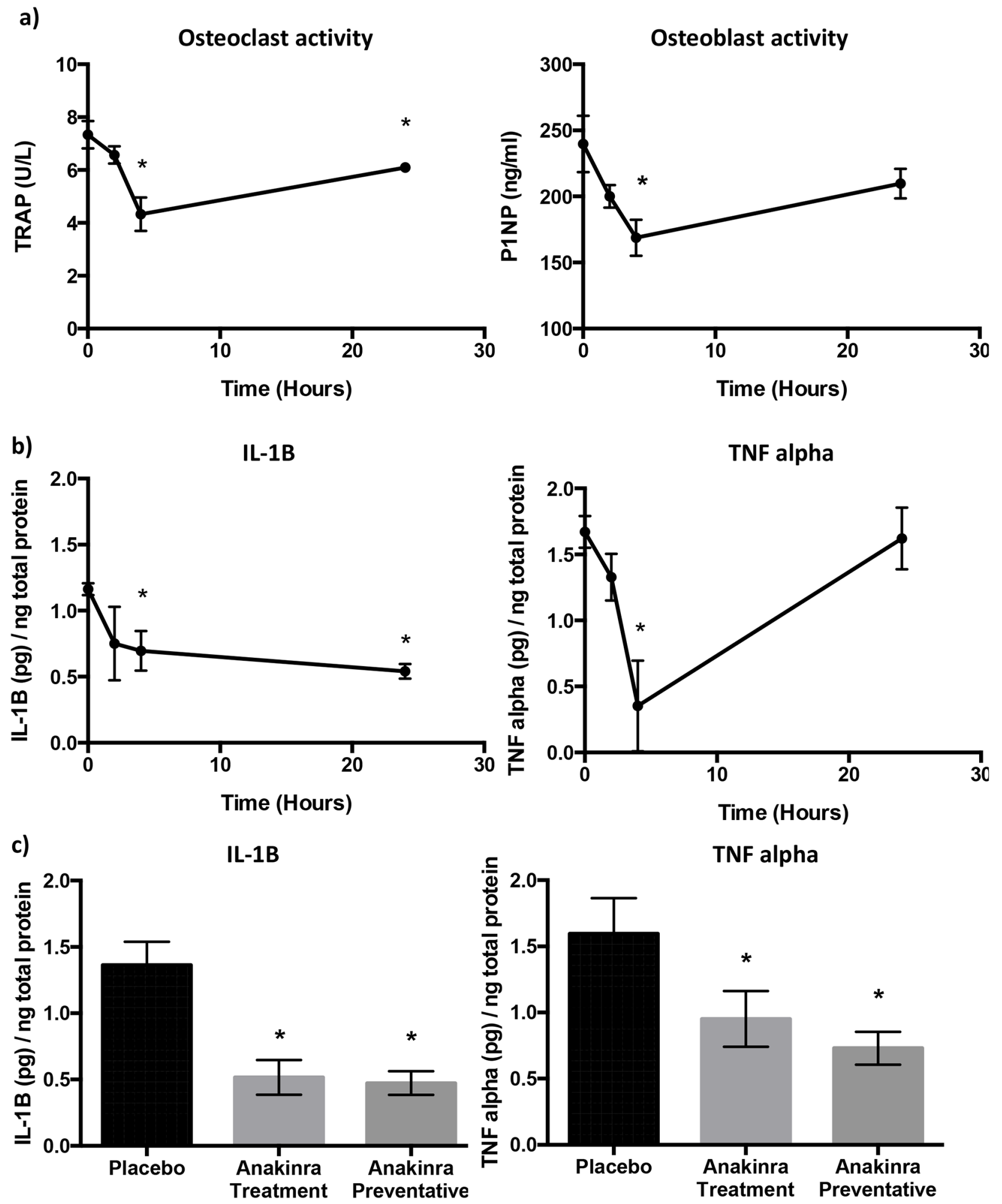

Figure 3: Effects of inhibition of IL-1R signalling on bone cell activity and cytokines. ELISA analysis of protein lysates of whole mouse bone. Bone turnover was measured by TRAP (osteoclast activity) and P1NP (osteoblast activity) 0, 2, 4 and 24h after administration of a single dose of $1 \mathrm{mg} / \mathrm{kg}$ anakinra a. Concentrations of pro-inflammatory cytokines IL-1B, and TNF alpha $0,2,4$ and $24 \mathrm{~h}$ after administration of a single dose of $1 \mathrm{mg} / \mathrm{kg}$ anakinra are shown in panel $\mathbf{b}$. Concentrations of IL-1B and TNF alpha in placebo and mice treated with $1 \mathrm{mg} / \mathrm{kg} /$ day anakinra for 24 or 31 days are shown in panel $\mathbf{c}$. Data shown are mean $+/-\mathrm{SEM}$ from 5 mice per group. ${ }^{*}=\mathrm{p}<0.05$. 
$(\mathrm{P}>0.0001)$ (Figure 5a and 5b). MCF7 tumours isolated from the preventative group were too small to allow ex-vivo analysis, therefore the anti-tumour effects of anakinra were assessed in isolated MDA-MB-231-IV tumours: Tumour cell apoptosis, assessed following immunohistochemistry for active Caspase 3 , was not

a)
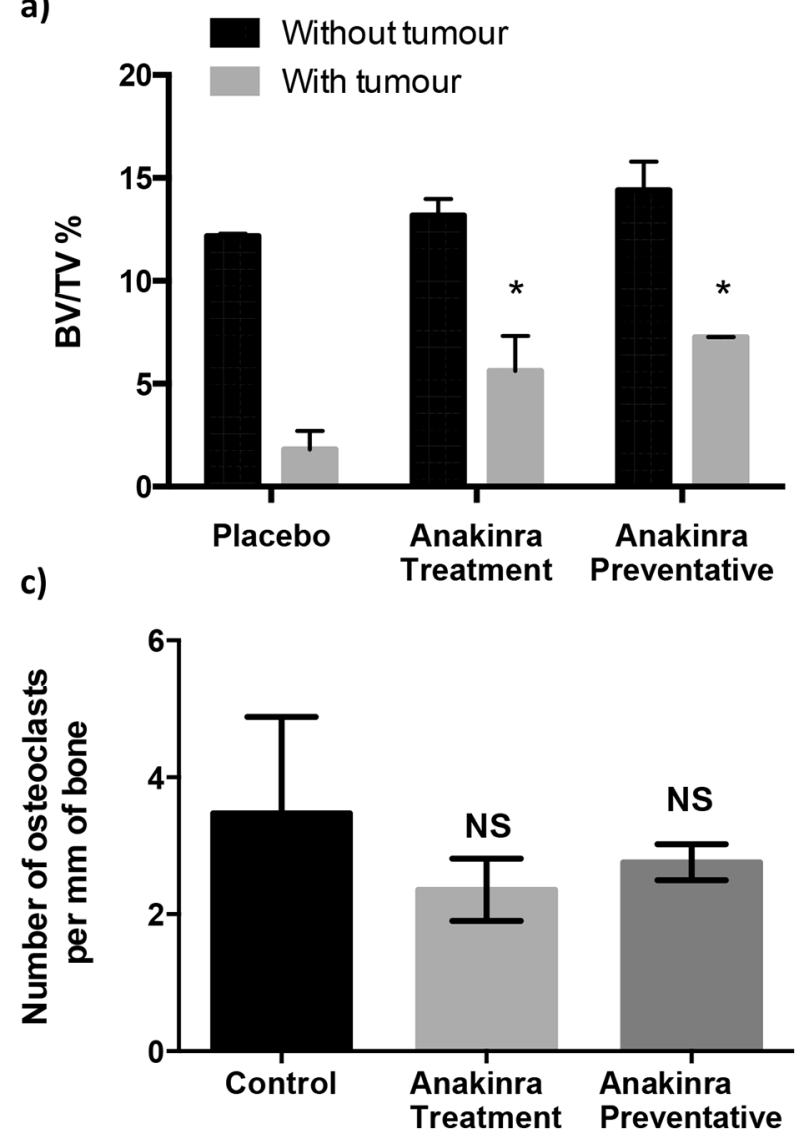

e)

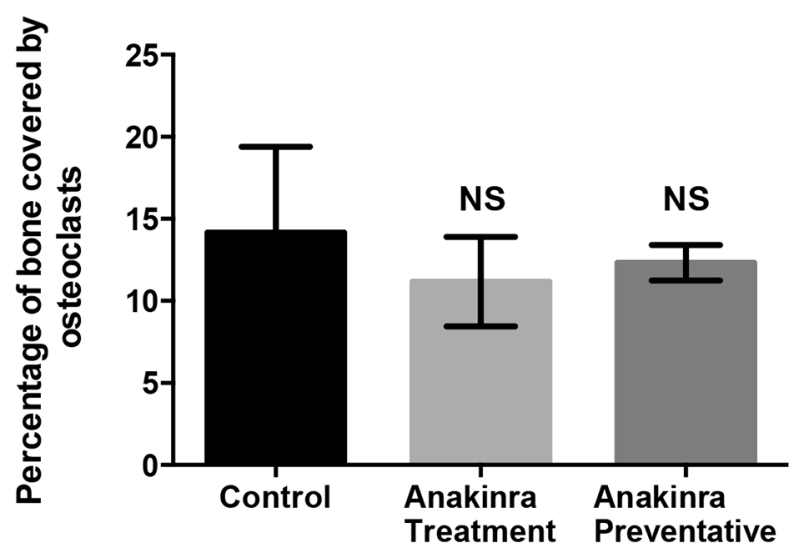

altered following daily injection with anakinra (Figure $5 \mathrm{c}$ and $5 \mathrm{~g}$ ), however necrotic cell death was significantly increased $(\mathrm{P}<0.01$ for treatment and $\mathrm{P}<0.001$ for preventative compared with placebo) (Figure 5d). Proliferation was significantly reduced with tumours from placebo treated mice containing $247.8+/-29.25$ Ki67

b)

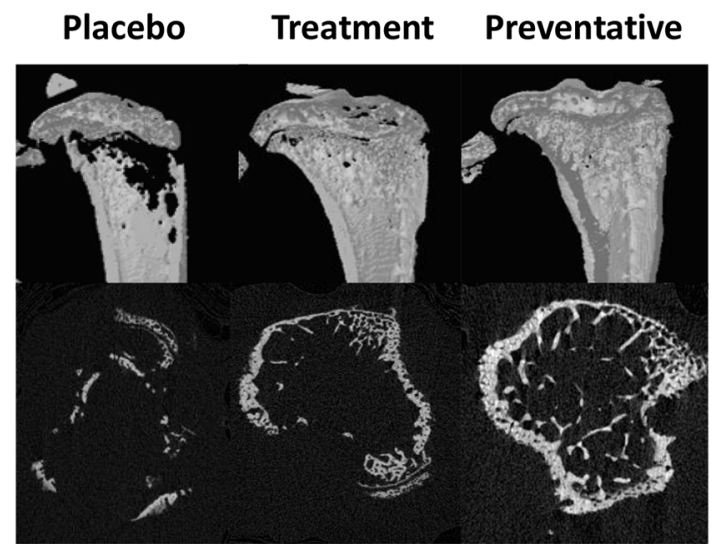

d)

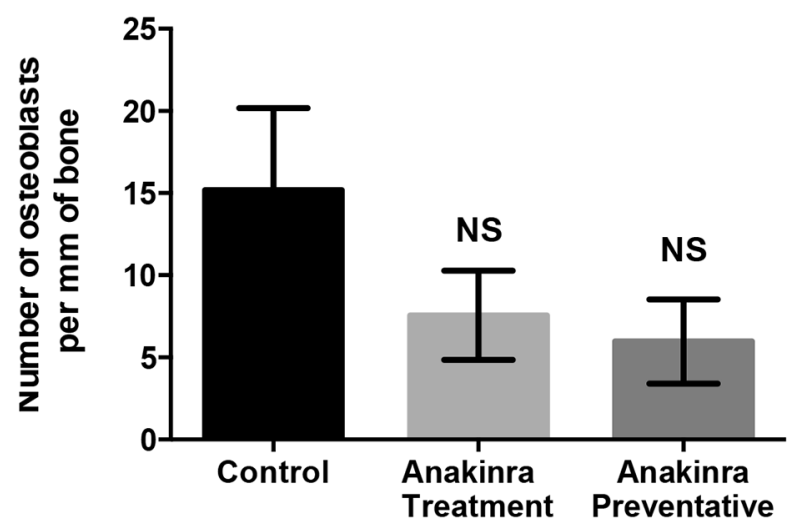

f)

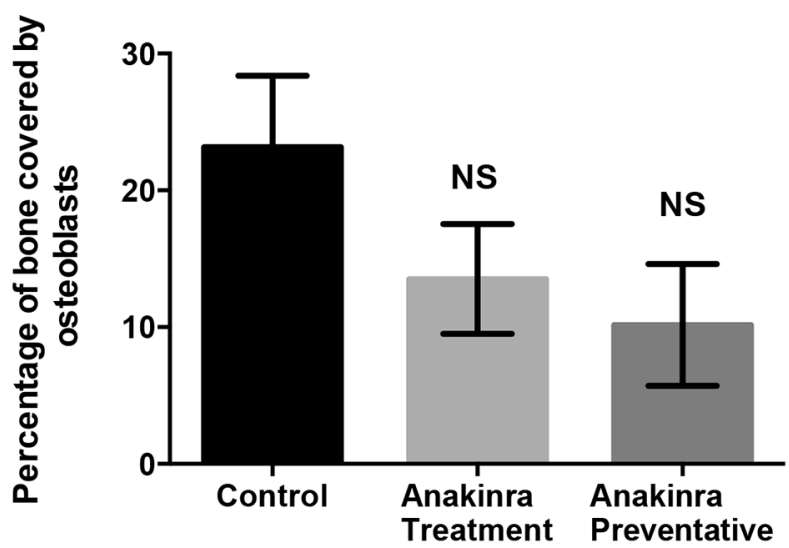

Figure 4: Effects of continuous IL-1R inhibition with anakinra on bone. Histogram showing mean $+/$ - SEM bone volume/tissue volume $(\mathrm{BV} / \mathrm{TV}) \%$ for trabecular bone in tibiae with and without tumours $\mathbf{a}$. and uCT images of tumour bearing tibiae from mice treated with placebo or $1 \mathrm{mg} / \mathrm{kg}$ anakinra/day using the treatment or preventative protocol $\mathbf{b}$. Numbers of osteoclasts c. and osteoblasts d. lining trabecular bones and percentage of bone covered in osteoclasts e. and osteoblasts f. are from tumour bearing tibiae of mice treated with placebo or anakinra using the treatment or preventative protocols. Data shown are (mean $+/-\mathrm{SEM}), *=\mathrm{P}<0.01$ compared with placebo. 
a)

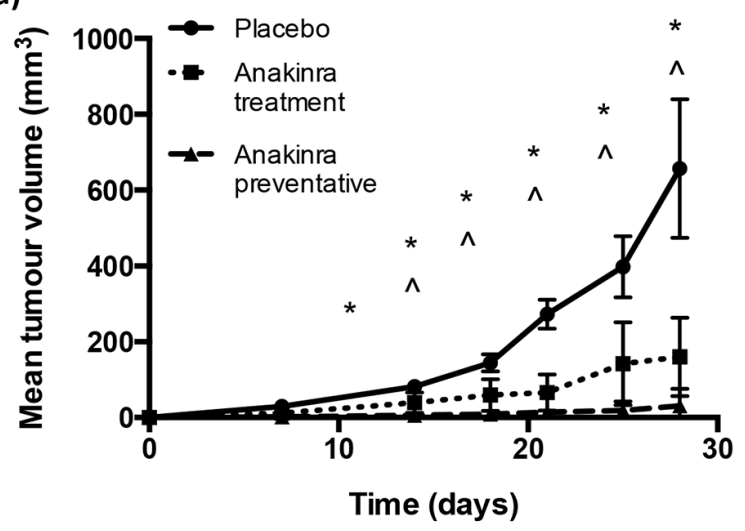

c)

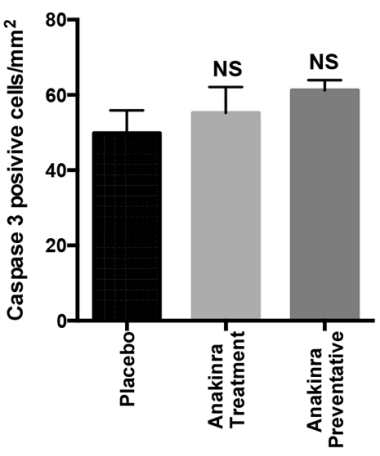

d)

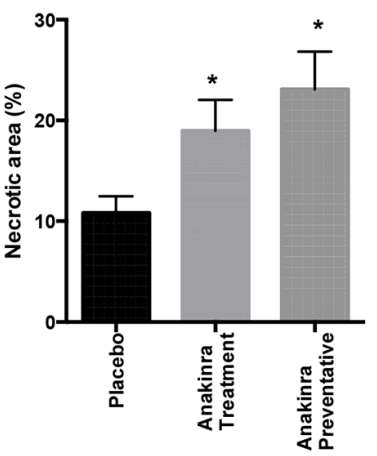

b)

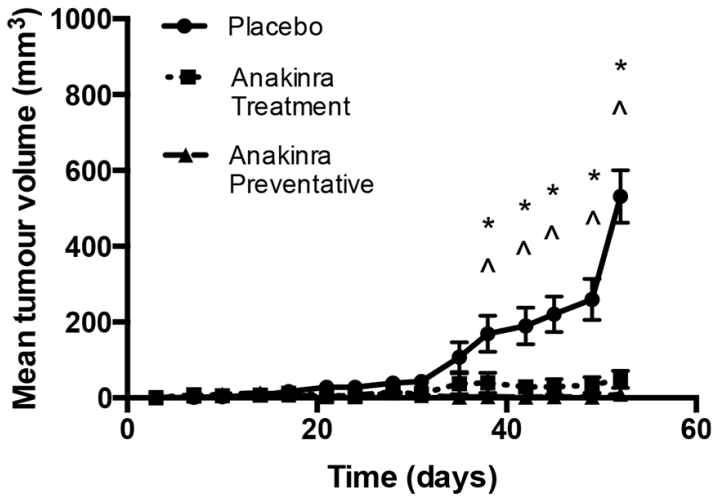

e)

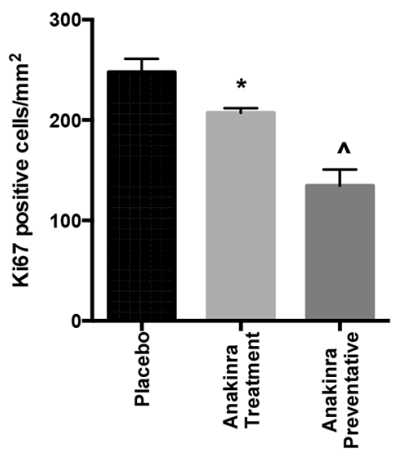

f)

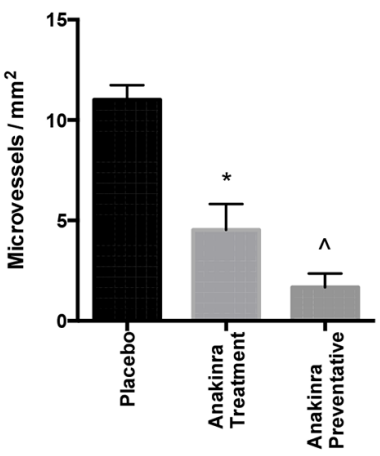

g) Caspase 3

Ki67

CD34

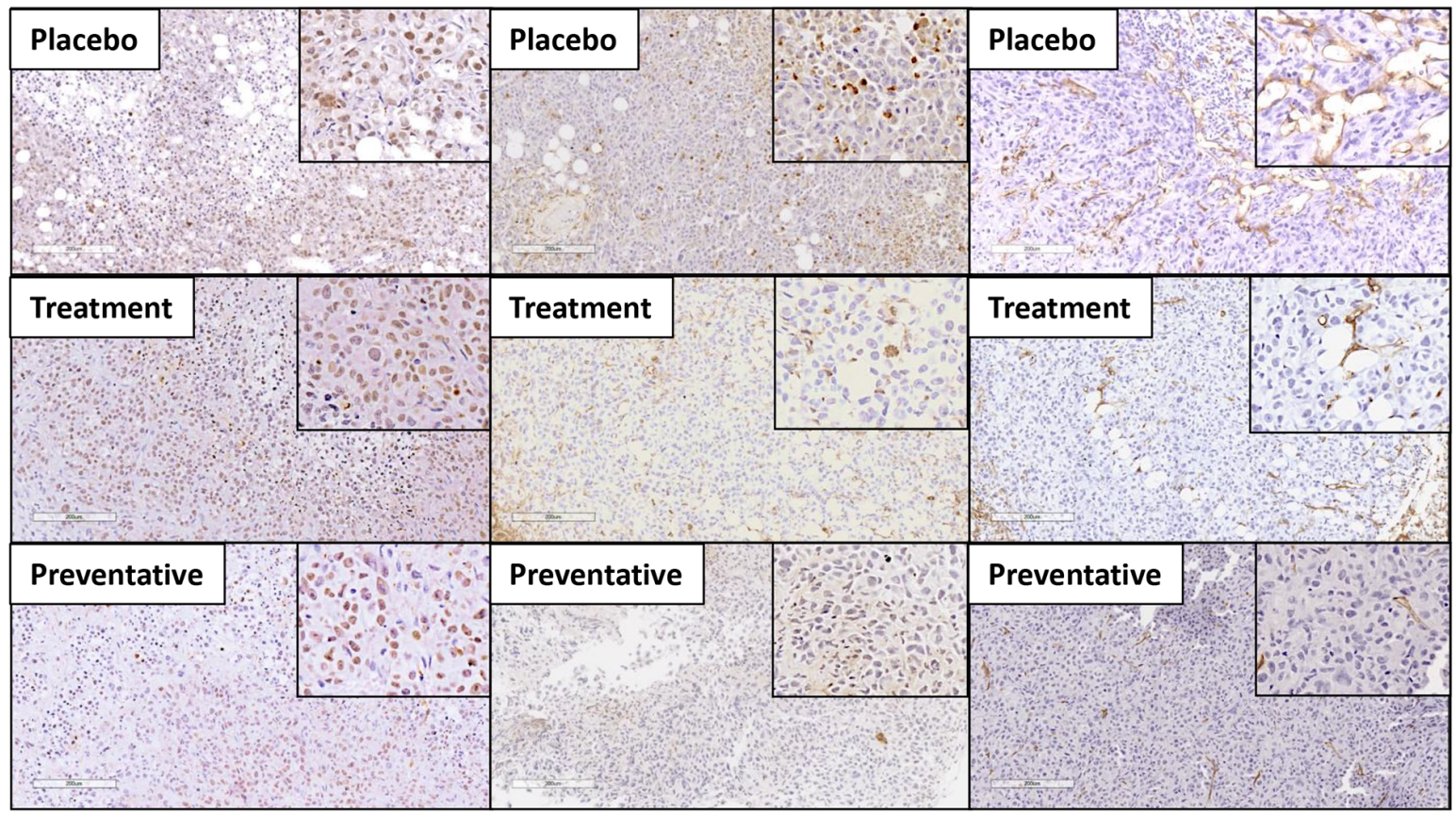

Figure 5: Effects of anakinra on subcutaneous MDA-MB-231-IV and MCF7 tumours. MDA-MB-231-IV or MCF7 cells were grown subcutaneously and mice treated with placebo or $1 \mathrm{mg} / \mathrm{kg} /$ day anakinra using the treatment or preventative protocol. Graphs show tumour volume for MDA-MB-231-IV cells a. and MCF7 cells b. Scoring data is for MDA-MB-231 tumours, number of active caspase 3 positive cells per $\mathrm{mm}^{2}$ of tumour c. $\%$ of tumour that is necrotic d. number of Ki67 positive cells per mm ${ }^{2}$ tumour e. and number of CD34 positive vessels per $\mathrm{mm}^{2}$ tumour f. mean +/- SEM. Representative X20 photomicrographs of subcutaneous tumours following immunohistochemical staining for active caspase 3, Ki67 and CD34 are shown in panel $\mathbf{g} . *{ }^{*}=\mathrm{p}<0.01$ compared with placebo, ${ }^{\wedge}=\mathrm{P}<0.01$ compared with placebo or treatment protocol. 
positive cells per $\mathrm{mm}^{2}$, this was reduced in tumours from mice receiving anakinra via the treatment protocol to $207.21+/-10.38$ cells per $\mathrm{mm}^{2}(\mathrm{P}<0.01)$ and to 134.65 $+/-36.08$ in tumours from mice administered anakinra using the preventative protocol $(\mathrm{P}<0.001)$ (Figure 5e and $5 \mathrm{~g}$ ). In accordance with the decreased angiogenesis induced by anakinra in MDA-MB-231-IV tumours growing in bone, histological analysis of tumour sections stained for the endothelial cell marker CD34 showed reduced angiogenesis in subcutaneous MDA-MB-231IV tumours from mice that had received daily anakinra compared with placebo. Compared with placebo, the number of CD34 positive microvessels in subcutaneous tumours decreased by $81 \%$ following administration of anakinra via the treatment protocol $(\mathrm{P}<0.01)$ and by $94 \%$ following the preventative protocol $(\mathrm{P}<0.001)$ (Figure 5f-5g).

These data show that inhibition of IL-1R signalling with anakinra significantly reduces subcutaneous growth of both ER+ve and ER-ve tumours and analysis of MDAMB-231-IV derived tumours support that this is mediated by altering the tumour microenvironment, increasing tumour cell necrosis and reducing proliferation and angiogenesis.

\section{DISCUSSION}

The primary aim of this study was to investigate the effects of blocking IL-1B activity through inhibition of the IL-1R, on breast cancer bone metastasis. Our data show that daily administration of the IL-1R antagonist anakinra significantly reduces development and progression of breast cancer bone metastases. This did not appear to be a result of reduced ability of MDA-MB-231-IV cells to locate to bone as originally hypothesised [1]. It is well established that following dissemination of MDAMB-231 cells in bone only a small number $(>0.1 \%)$ proliferate into overt metastasis whilst the rest remain dormant [25]. Labelling MDA-MB-231-IV cells with DiD before injection enabled quantification of tumour cells that had disseminated in the bone environment and remained dormant throughout the experimental period [23, 25-26]. Pre-treatment with anakinra 3-days before inoculation of tumour cells had no effect on the number of non-proliferative cells detected in bone, therefore, it is likely that administration of anakinra did not affect tumour cell dissemination in bone. Instead, our data indicate that inhibition of IL-1R with anakinra inhibits proliferation of tumour cells within bone, holding these in a dormant state and subsequently preventing progression to metastases. The increased anti-tumour effects observed with the preventative protocol compared with the treatment protocol may be due in part to the extended time period in which anakinra can exert an effects (31 vs. 21 days) in addition to micrometastases already being present in mice from the treatment protocol before the administration of anakinra. Anakinra reduced the numbers of mice in which tumours developed into overt metastases, not by directly killing tumour cells through induction of apoptosis, but by reducing tumour cell proliferation and angiogenesis. Our data suggest that these anti-tumour effects are a result of changes in the tumour microenvironment, as direct incubation of MDA-MB-231-IV cells with anakinra did not exert anti-tumour affects in vitro (Supplementary Figure S1). The bone is rich in remodelling cytokines, including TNF alpha, IL-1B and IL-6, and previous studies have reported that incubation of MDA-MB-231 cells with a combination of these cytokines in a $3 \mathrm{D}$ model system stimulates their proliferation [24]. In our study, administration of anakinra significantly reduced expression of TNF alpha and IL-1B in bone (Figure 3) and reduced levels of these molecules is likely to have contributed to the anti-tumour effects observed.

Bone metastases are traditionally associated with increased bone turnover. It is generally accepted that breast cancer cells growing in bone release growth factors that stimulate osteoclastic bone resorption and the release of growth factors from bone that, in turn, stimulate growth of the tumour; a process is known as the vicious cycle [28]. Based on this theory and evidence from mouse model systems, we hypothesise that increasing bone turnover would result in increased metastases from tumour cells disseminated in this site and current clinical practise as well as our previous work has focussed on inhibiting bone resorption to treat bone metastases [18, 22-23, 29]. Removal of IL-1B or IL-1R1 in mouse knockout models has profound effects on the bone microenvironment, resulting in reduced bone resorption, increased trabecular thickness and skeletal growth, suggesting that silencing of central IL-1R signalling leads to progressive accrual of bone mass [30-31]. In the current study, anakinra significantly reduced osteoclastic bone resorption and osteoblastic bone formation within $4 \mathrm{~h}$ of administration, these returned to near normal levels by $24 \mathrm{~h}$ when the next dose was administered. Overall, this dosing regime led to a small reduction in the number of osteoclasts or osteoblasts on the bone surface and although there was a trend towards increased bone volume this did not reach significance (Figures 3 and 4). It is, therefore, possible that anti-tumour effects of anakinra may partially be the result of reduced bone turnover, however, it is more likely that the substantially lower bone tumour burden observed in mice treated with this agent is the result of inhibition of tumour cell proliferation and angiogenesis.

Vascular endothelial cells secrete pro-inflammatory cytokines, including IL-1B and TNF alpha [32], with increased expression of the latter linked with increased expression of endothelins [33]. In accordance with previously published data showing reduced primary tumour growth and CD34 positive vasculature in 4T1 mammary tumours treated with anakinra [24], our study also showed that inhibition of MDA-MB-231-IV tumour 
growth in bone following administration of anakinra was associated with reduced levels of CD34 positive blood vessels. Further analysis revealed that daily administration of anakinra significantly reduced endothelin 1 gene expression in both mouse bone and human tumours. These data imply that there is a feedback between cytokine production and development of new endothelial cells, and that blocking IL-1B and TNF alpha production with anakinra reduces the formation of new blood vessels, thereby starving the tumour of nutrients and oxygen. In contrast to previous studies showing increased VEGF expression in endothelial cells treated with IL-1B [34] and reduced IL-1B and TNF alpha activity in bone marrow mononuclear cells stimulated with VEGF [35], we did not see a significant decrease in VEGF gene expression in either mouse bone or MDA-MB-231-IV tumours growing in bone following administration of anakinra, compared with placebo. We know that VEGF signalling is complex and tumour heterogeneity as well as redundancy in the VEGF signalling system result in resistance to anti-VEGF therapies in cancer patients including those with breast cancer [Reviewed in: 36-37]. The role that cytokines like IL-1B play in this redundancy remains to be established.

The anti-tumour effects of anakinra were not confined to tumours in bone. This may indicate that alterations to the bone microenvironment are not the sole reason for reduced tumour growth, however, we cannot discount the possibility that anakinra may affect vascular precursors within the bone marrow; further investigations are required to address this question. Daily treatment of mice with anakinra starting 7 days after subcutaneous injection of MDA-MB-231-IV or MCF7 cells significantly reduced tumour growth which was further reduced when mice were pre-treated with anakinra for 3-days before tumour cell implantation. As with MDA-MB-231-IV cells growing in bone, reduced tumourigenesis was not due to an increase in cell death by apoptosis but an increase in tumour cell necrosis, reduction in tumour cell proliferation and angiogenesis. These data suggest that anakinra causes changes in the subcutaneous tumour microenvironment, possibly via reduced IL-1B and TNF alpha signalling on endothelial cells preventing neo-angiogenesis and reducing nutrient/oxygen supply to the growing tumours. Our findings are in agreement with previously published studies showing that treatment of subcutaneous MCF7 tumours with a combination of tamoxifen, flaxseed and eterolactone resulted in production of a naturally occurring IL-1 receptor antagonist from the tumours and these tumours exhibited reduced growth and angiogenesis [38]. Similarly, studies in mouse models of Lewis Lung and 4T1 mammary cancer, showed decreased growth of primary tumours following administration of paclitaxel, anakinra or a combination of the two [24]. In this study, administration of paclitaxel increased secretion of IL$1 \mathrm{~B}$ and subsequent development of lung metastases, leading the authors to hypothesise that increased IL-1B was driving metastasis. However, this study subsequently reported that administration of a high dose (10mg/ $\mathrm{kg}$ ) anakinra for 3 consecutive days starting $24 \mathrm{~h}$ before paclitaxel $(25$ or $50 \mathrm{mg} / \mathrm{kg}$ ) did not inhibit metastasis. Using this high dose of anakinra appeared to increase lung metastasis, increase leakage from blood vessels and increase numbers of tumour-associated macrophages [24]. It is important that decreased bone metastasis seen following administration of anakinra is not replaced by increased lung metastasis. In our current study, we used bone seeking MDA-MB-231-IV cells, these cells rarely metastasise to lung $(\sim 2 \%)$ and daily treatment with $1 \mathrm{mg} /$ $\mathrm{kg}$ anakinra did not induce lung metastasis. Furthermore, using this lower dose of anakinra did not affect numbers of tumour-associated macrophages found in bone metastases. It is possible that the lack of T cells our mouse models is the reason that we did not see increased lung metastasis following anakinra and the role of the immune system warrants further investigation. It should also noted that anakinra has a half life of 4-6 h [39] and concentrations of IL-1B spike to above background levels $48 \mathrm{~h}$ after withdrawal of high doses of this antagonist $(3-10 \mathrm{mg} / \mathrm{kg}$ ) [40], therefore, increased IL-1 after anakinra withdrawal may promote lung metastasis in the Lewis lung and 4T1 models. Withdrawal of clinically relevant doses of anakinra $(1 \mathrm{mg} / \mathrm{kg} /$ day) used in the current study is not reported to induce a spike in circulating IL-1B, indicating that this dose may be more effective for treating breast cancer metastasis. Further investigations are needed to establish whether continuous treatment with anakinra is necessary for sustained inhibition of metastasis.

Anakinra inhibits the IL-1R-mediated signalling by both IL-1B and IL-1A. We cannot be sure to what extent the observed anti-tumour effects are due to reduced IL-1B signalling. It is possible that inhibition of IL-1A, as well as downstream effects on other cytokines including TNF alpha, contribute to the reduced of growth of both subcutaneous and bone tumours following administration of anakinra. There are a number of reports showing the pro-tumourigenic effects of TNF alpha in breast cancer [reviewed in 41]. However, independent of the mechanism by which anakinra reduces growth of MCF7 and MDA-MB-231-IV breast tumours, blocking IL-1R may be of therapeutic benefit to breast cancer patients. Anakinra (up to $100 \mathrm{mg}$ /day; equivalent to the $1 \mathrm{mg} /$ day in mice used in this study) is licenced to treat patients with neonatal onset multi system inflammatory disease and rheumatoid arthritis [13-14]. Anakinra is generally well tolerated and severe side effects (neutropenia and hepatotoxicity) are rare, the main disadvantage being the requirement for daily injections. Clinical trials of anakinra in breast cancer to investigate the clinical significance of our findings could therefore be initiated relatively easily.

In conclusion, our data provide the first evidence that continuous inhibition of IL-1 activity inhibits breast tumour growth and progression to bone metastasis in vivo. Inhibition of IL-1R with a clinically relevant dose 
of anakinra significantly alters the tumour and bone microenvironments leading to reduced tumour cell proliferation and angiogenesis and increased tumour cell necrosis as well as reduced bone turnover. These findings indicate that IL-1 may provide a potential novel therapeutic target for breast cancer bone metastasis.

\section{MATERIALS AND METHODS}

\section{Cell culture}

MCF7 cells (European Collection of Authenticated Cell Cultures) and an eGFP expressing bone homing derivative of MDA-MB-231 produced in house, MDA-MB231-IV [1] were maintained in RPMI-1640 supplemented with 10\% FCS (Gibco Invitrogen, Paisley UK). Both cell lines were authenticated, in house, using short tandem repeat analysis of 10 loci. Prior to in vivo inoculation, eGFP expressing cells were incubated for 15 minutes with $25 \mu \mathrm{M}$ of 1,1 '-Dioctadecyl-', 3'-Tetramethylindodicarbocya nine, 4-Chlorobenzenesulfonate (DiD) (Life Technologies, Paisley, UK) to enable detection of disseminated tumour cells in bone by two-photon microscopy. Tumour growth was monitored in vivo using an Illumatool Lighting System (LightTools Research, Encintas, CA) (eGFP).

\section{In vitro studies}

Cell proliferation was monitored every $24 \mathrm{~h}$ for 144 hours by manual cell counting using a $1 / 400^{2}$ haemocytometer (Hawksley, Lancing, UK). Tumour cell invasion was assessed using $6 \mathrm{~mm}$ Transwell plates with an $8.0 \mu \mathrm{M}$ pore size (Costar; Corning Incorporated, NY, USA) coated with basement membrane matrix (20\% Matrigel; Invitrogen, Paisley, UK). Cells were seeded into the inner chamber at a density of $2.5 \times 10^{5}$ for MDA-MB-231-IV and $5 \times 10^{5}$ for MCF7 in RPMI without FCS and $5 \times 10^{5}$ HS5 bone marrow cells in RPMI supplemented with 10\% FCS were added to the outer chamber. Cells were removed from the top surface of the membrane 24 and 48 hours after seeding, and cells that have invaded through the pores were stained with haematoxylin and eosin before being imaged on Leica DM7900 light microscope and manually counted.

Migration of cells was investigated by analysing wound closure: Cells were seeded onto $0.2 \%$ gelatine in 6-well tissue culture plates (Costar; corning incorporated); once confluent, $10 \mathrm{ug} / \mathrm{ml}$ mitomycin $\mathrm{C}$ was added to inhibit cell proliferation and a 50uM scratch made across the monolayer. The percentage of wound closure was measured 24 and 48 hours using a CTR7000 inverted microscope and LAS-AF v2.1.1 software (Leica Applications Suite; Leica Microsystems, Wetzlar, Germany).

\section{In vivo studies}

Tumour growth studies used 6-week-old female $\mathrm{BALB} / \mathrm{c}$ nude mice (13-16g) to enable modelling of bone metastasis. To investigate the effects of anakinra on circulating cytokines we used BALB/c wild-type and immunocompromised mice (Charles River, Kent, UK). Experiments were carried out in accordance with local guidelines and with Home Office approval under project licence 40/3462, University of Sheffield, UK.

To investigate the effects on serum levels of IL-1B, TNF alpha and IL6, $1 \mathrm{mg} / \mathrm{kg}$ anakinra (r-metHu1L-ra, equivalent to $100 \mathrm{mg}$ currently licenced to treat rheumatoid arthritis) or placebo (control) (Amgen, Cambridge, UK) was injected subcutaneously (s.c) into 20 mice. Mice were culled 0, 2, 4 and $24 \mathrm{~h}$ after injection. Bone marrow and serum were collected and stored at $-80^{\circ} \mathrm{C}$ prior to analysis.

To assess the effects of on initiation of tumour development in soft tissue and in bone, mice were pretreated with $1 \mathrm{mg} / \mathrm{kg} /$ day anakinra or placebo starting 3 -days before injection of $5 \times 10^{6} \mathrm{MCF} 7$ or $0.5 \times 10^{6} \mathrm{MDA}-$ MB-231-IV cells s.c. or intra-venously (i.v.) via the lateral tail vein ( $n=8 /$ group/experiment). To investigate whether anakinra reduces growth of established tumours in soft tissue and bone, $0.5 \times 10^{5}$ MDA-MB-231-IV cells were injected s.c. or i.v. ( $\mathrm{n}=8 /$ group/experiment) 7 days prior to commencement of anakinra treatment. Each experiment was repeated twice and mice injected with MDA-MB231-IV cells were culled 35 days (experiment 1) or 28 days (experiment 2) after tumour cell injection. Mice injected with MCF7 cells were supplemented with 4mg/L B-estradiol (Sigma Aldrich, Poole, UK) via their drinking water and culled 56 days after tumour cell injection.

Serum was stored at $-80^{\circ} \mathrm{C}$ for ELISA, tibiae and femurs were fixed in 4\% PFA for microcomputed tomography $(\mu \mathrm{CT})$ analysis before decalcification in $1 \%$ PFA $/ 0.5 \%$ EDTA and processing for histology. Bones for two-photon analysis were stored in OCT at $-80^{\circ} \mathrm{C}$.

\section{Microcomputed tomography imaging}

$\mu \mathrm{CT}$ analysis was carried out using a Skyscan 1172 x-ray-computed $\mu \mathrm{CT}$ scanner (Skyscan, Aartselar, Belgium) equipped with an $\mathrm{x}$-ray tube (voltage, $49 \mathrm{kV}$; current, 200uA) and a $0.5-\mathrm{mm}$ aluminium filter. Pixel size was set to $5.86 \mathrm{~mm}$ and scanning initiated from the top of the proximal tibia as previously described [18].

\section{Bone histology and measurement of tumour volume}

Subcutaneoustumour volume was measured twice per week using vernier callipers. Bone tumour areas were measured on3, non-serial, H\&E stained,5mM histological sections of decalcified tibiae per mouse using Osteomeasure software (Osteometrics inc. Decauter, USA) and a computerised image analysis system.

Osteoclasts were detected by tartrate-resistant acid phosphatase (TRAP) staining as previously described [19]. Osteoblasts were identified as mononuclear, cuboidal cells residing in chains along the bone surface. 
The number of osteoclasts/osteoblasts per mm of corticalendosteal bone surface and trabecular bone surfaces and the proportion of bone surface occupied by osteoclasts/ osteoblasts was determined using a Leica RMRB upright microscope and OsteoMeasure software as previously described [20].

\section{Immunohistochemistry and in situ hybridization}

Immunohistochemistry for caspase-3 was performed using a rabbit polyclonal antibody that specifically recognizes active mouse caspase-3 (AF835, 1:750 dilution; R\&D Systems, Minneapolis, MN), followed by a biotin-conjugated anti-rabbit secondary antibody (1:200 dilution; Vector Laboratories, Peterborough, UK.) as described by Marshman et al. [21]. Immunohistochemistry for the cell proliferation antigen Ki-67 was carried out as previously described [22] using a mouse monoclonal antibody specific for human Ki-67 (MIB-1, 1:125 dilution; DakoCytomation, Cambridge, UK) followed by a biotinconjugated anti-mouse secondary antibody (1:200; Vector Laboratories). The endothelial cell antigen CD34 and macrophage specific antigen F4/80 were detected as described for $\mathrm{Ki}-67$ with the use of a rat monoclonal antibodys specific for mouse CD34 (MCA1825GA, 1:50 dilution; Serotec, Oxford, UK) or mouse F4/80 1:100 dilution; BioRad, Oxford, UK) followed by a biotinconjugated anti-rat secondary antibody (E0467, 1:200 dilution; DakoCytomation). In situ hybridization to detect cells in the early stages of apoptosis was performed using a Millipore ApopTag® Peroxidase in situ Apoptosis detection kit (TUNEL) and manufacturers instructions (Merck Millipore, Durham, UK).

Necrosis, apoptosis and proliferation were scored on two stained histological sections per tumor sample. $\%$ Area of necrotic tumour was measured following H\&E staining and numbers of active caspase-3-positive, TUNEL positive or Ki-67-positive cells innon-necrotic tumourwere counted with the use of an Leica BMRB upright microscope and OsteoMeasure software. Quantification of microvasculature was established by quantifying the mean number of CD34 positive stained blood vessels through a Chalkley grid count. Briefly, a 25-point grid was placed over a $20 \mathrm{X}$ magnification lens of a Leica RNRB upright microscope; all vellels touching the grid were counted. 5 randomly selected fields of nonnecrotic tumour were scored on 2 non-serial sections per tumour.

\section{Two-photon microscopy}

Tibiae were imaged using a multiphoton confocal microscope (LSM510 NLO upright; Zeiss, Cambridge, UK). DiD labelled cells were visualised using a $900 \mathrm{~nm}$ Chameleon laser, bone was detected using the $633 \mathrm{~nm}$ multiphoton laser (Coherent, Santa Clara, CA.) and images were reconstructed in LSM software version 4.2 (Zeiss) as previously described [23].

\section{Biochemical analysis}

Serum concentrations of TRACP-5b and P1NP were measured using commercially available ELISA kits: MouseTRAPTM Assay (Immunodiagnostic Systems) and Rat/Mouse P1NP competitive immunoassay kit (Immunodiagnostic Systems), respectively. Concentrations of IL-1B, TNF alpha and IL-6 were analysed in mouse bone marrow and serum using anti-mouse Quantikine ELISA kits (R\&D systems, Abingdon, UK) and manufacturers protocols.

\section{Real-time PCR}

Mouse and human VEGF and endothelin 1 gene expression was analysed on cDNA isolated from tumourbearing mouse bones using Taqman assays (VEGF: Hs00900055_m1 (human) Mm01281449 (mouse); endothelin 1: Hs00174961 (human) Mm00438656 (mouse)) (all reagents from Applied Biosystems, Warrington UK): Relative gene expression compared with the housekeeping gene glyceraldehyde-3-phosphate dehydrogenase (GAPDH; Hs99999905_m1) was assessed using an ABI 7900 PCR System (Perkin Elmer, Foster City, CA) and Taqman universal master mix). Fold change in gene expression between treatment groups was assessed by directly inserting CT values into Data Assist V3.01 software (Applied Biosystems) and changes in gene expression were only analysed for genes with a CT value of $\leq 25$.

\section{Statistical analysis}

Statistical analysis was by unpaired T-test except for Kaplan-Meier survival charts for which one tailed MantelHansel and log-rank tests for trend were used. All analysis were carried out using GraphPad PRISM $®$ software version 6.0. Statistical significance was defined as P less than or equal to 0.05 .

\section{ACKNOWLEDGMENTS}

We would like to thank Mrs Alyson Evans and Miss Mary del Carmen Erazo Basitdas for their technical input.

\section{FUNDING}

This study was supported by a project grant from Weston Park Hospital Cancer Charity and The Department of Oncology, University of Sheffield.

\section{CONFLICTS OF INTEREST}

Authors have no conflicts of interest to declare. 


\section{REFERENCES}

1. Nutter F, Holen I, Brown HK, Cross SS, Evans CA, Walker M, Coleman RE, Westbrook JA, Selby PJ, Brown JE, Ottewell PD. Different molecular profiles are associated with breast cancer cell homing compared with colonisation of bone: evidence using a novel bone-seeking cell line. Endocr Relat Cancer. 2014; 21:327-41.

2. Lewis AM, Varghese $\mathrm{S}, \mathrm{Xu} \mathrm{H}$, Alexander HR. Interleukin-1 and cancer progression: the emerging role of interleukin-1 receptor antagonist as a novel therapeutic agent in cancer treatment. J Transl Med. 2006; 10;4:48.

3. Paquette B, Therriault H, Wagner JR. Role of interleukin-1 $\beta$ in radiationenhancement of MDA-MB-231 breast cancer cell invasion. Radiat Res. 2013; 180:292-8.

4. Ma L, Lan F, Zheng Z, Xie F, Wang L, Liu W, Han J, Zheng F, Xie Y, Huang Q. Epidermal growth factor (EGF) and interleukin (IL)-1 $\beta$ synergistically promote ERK1/2mediated invasive breast ductal cancer cell migration and invasion. Mol Cancer. 2013; 21;11:79.

5. Soria G, Ofri-Shahak M, Haas I, Yaal-Hahoshen N, LeiderTrejo L, Leibovich-Rivkin T, Weitzenfeld P, Meshel T, Shabtai E, Gutman M, Ben-Baruch A. Inflammatory mediators in breast cancer: coordinated expression of TNF $\alpha 1 \&$ IL- $1 \beta$ with CCL2 \& CCL5 and effects on epithelial-to-mesenchymal transition. BMC Cancer. 2011; 11:130.

6. Franco-Barraza J, Valdivia-Silva JE, Zamudio-Meza H, Castillo A, García-Zepeda EA, Benítez-Bribiesca, Meza I. Actin cytoskeleton participation in the onset of IL-1beta induction of an invasive mesenchymal-like phenotype in epithelial MCF-7 cells. Arch Med Res. 2010; 41:170-81.

7. Liu Q, Russell MR, Shahriari K, Jernigan DL, Lioni MI, Garcia FU, Fatatis A. Interleukin-1 $\beta$ promotes skeletal colonization and progression of metastatic prostate cancer cells with neuroendocrine features. Cancer Res. 2013; 73:3297-305.

8. Saijo Y, Tanaka M, Miki M, Usui K, Suzuki T, Maemondo M, Hong X, Tazawa R, Kikuchi T, Matsushima K, Nukiwa T. Proinflammatory cytokine IL-1 beta promotes tumor growth of Lewis lung carcinoma by induction of angiogenic factors: in vivo analysis of tumor-stromal interaction. J Immunol. 2002; 169:469-75.

9. Gemma A, Takenaka K, Hosoya Y, Matuda K, Seike M, Kurimoto F, Ono Y, Uematsu K, Takeda Y, Hibino S, Yoshimura A, Shibuya M, Kudoh S. Altered expression of several genes in highly metastatic subpopulations of a human pulmonary adenocarcinoma cell line. Eur J Cancer. 2001; 37:1554-61.

10. 10. Yoshino Y, Aoyagi M, Tamaki M, Duan L, Morimoto T, Ohno K. Activation of p38 MAPK and/or JNK contributes to increased levels of VEGF secretion in human malignant glioma cells. Int J Oncol. 2006; 29:981-7.
11. Elaraj DM, Weinreich DM, Varghese S, Puhlmann M, Hewitt SM, Carroll NM, Feldman ED, Turner EM, Alexander HR. The role of interleukin 1 in growth and metastasis of human cancer xenografts. Clin Cancer Res. 2006; 12:1088-96

12. Rodríguez-Berriguete G, Sánchez-Espiridión B, Cansino JR, Olmedilla G, Martínez-Onsurbe P, Sánchez-Chapado M, Paniagua R, Fraile B, Royuela M. Bone marrow adipocytes promote tumor growth in bone via FABP4-dependent mechanisms. Oncotarget. 2013; 4:2108-23. doi: 10.18632/ oncotarget.1482.

13. Kuemmerle-Deschner JB, Tyrrell PN, Koetter I, Wittkowski H, Bialkowski A, Tzaribachev N, Lohse P, Koitchev A, Deuter C, Foell D, Benseler SM. Efficacy and safety of anakinra therapy in pediatric and adult patients with the autoinflammatory Muckle-Wells syndrome. Arthritis Rheum. 2011; 63:840-9.

14. Mertens M, Singh JA. Anakinra for rheumatoid arthritis. Cochrane Database Syst Rev . 2009: CD005121

15. Morton AC, Rothman AM, Greenwood JP, Gunn J, Chase A, Clarke B, Hall AS, Fox K, Foley C, Banya W, Wang D, Flather MD, Crossman DC. The effect of interleukin-1 receptor antagonist therapy on markers of inflammation in non-ST elevation acute coronary syndromes: the MRC-ILA Heart Study. Eur Heart J. 2015; 36:377-84.

16. Dinarello CA. Why not treat human cancer with interleukin-1 blockade? Cancer and Metastasis Reviews. 2010; 29:317-329.

17. Lawrie A, Hameed AG, Chamberlain J, Arnold N, Kennerley A, Hopkinson K, Pickworth J, Kiely DG, Crossman DC, Francis SE. Paigen diet-fed apolipoprotein E knockout mice develop severe pulmonary hypertension in an interleukin-1-dependent manner. Am J Pathol. 2011; 179:1693-705.

18. Ottewell PD, Deux B, Mönkkönen H, Cross S, Coleman RE, Clezardin P, Holen I. Differential effect of doxorubicin and zoledronic acid on intraosseous versus extraosseous breast tumor growth in vivo. Clin Cancer Res. 2008; 14:4658-66.

19. Cole AA, Walters LM. Tartrate-resistant acid phosphatase in bone and cartilage following decalcification and coldembedding in plastic. J Histochem Cytochem. 1987; 35:203-206.

20. Parfitt AM, Drezner MK, Glorieux FH, Kanis JA, Malluche H, Meunier PJ, Ott SM, Recker RR. Bone histomorphometry: standardization of nomenclature, symbols, and units. Report of the ASBMR Histomorphometry Nomenclature Committee. J Bone Miner Res. 1987; 2:595-610.

21. Marshman E, Ottewell PD, Potten CS, Watson AJ. Caspase activation during spontaneous and radiation-induced apoptosis in the murine intestine. J Pathol. 2001; 195:285-92.

22. Ottewell PD, Mönkkönen H, Jones M, Lefley DV, Coleman RE, Holen I. Antitumor effects of doxorubicin followed by 
zoledronic acid in a mouse model of breast cancer. J Natl Cancer Inst. 2008; 100:1167-78.

23. Ottewell PD, Wang N, Brown HK, Reeves KJ, Fowles CA, Croucher PI, Eaton CL, Holen I. Zoledronic acid has differential antitumor activity in the pre- and postmenopausal bone microenvironment in vivo. Clin Cancer Res. 2014; 20:2922-32.

24. Voloshin T, Alishekevitz D, Kaneti L, Miller V, Isakov E, Kaplanov I, Voronov E, Fremder E, Benhar M, Machluf M, Apte RN, Shaked Y. Blocking IL1 $\beta$ Pathway Following Paclitaxel Chemotherapy Slightly Inhibits Primary Tumor Growth but Promotes Spontaneous Metastasis. Mol Cancer Ther. 2015; 14:1385-94.

25. Wang N, Reeves KJ, Brown HK, Fowles CM, Docherty FE, Ottewell PD, Croucher PI, Holen I, Eaton CL. The frequency of osteolytic bone metastasis is determined by conditions of the soil, not the number of seeds; evidence from in vivo models of breast and prostate cancer. J Exp Clin Can Res. 2015; 20;34:124

26. Ottewell PD, Wang N, Brown HK, Fowles CA, Croucher PI, Eaton C, Holen I. OPG-Fc inhibits ovariectomy-induced growth of disseminated breast cancer cells in bone. Int $\mathrm{J}$ Can. 2015; 15;137:968-77.

27. Sosnoski DM, Norgard RJ, Grove CD, Foster SJ, Mastro AM. Dormancy and growth of metastatic breast cancer cells in a bone-like microenvironment. Clin Exp Metastasis. 2015; 32:335-44.

28. Cook LM, Shay G, Araujo A, Lynch CC. Integrating new discoveries into the "vicious cycle" paradigm of prostate to bone metastases. Cancer Metastasis Rev. 2014; 33:511-25.

29. Coleman R, Body JJ, Aapro M, Hadji P, Herrstedt J; ESMO Guidelines Working Group. Bone health in cancer patients: ESMO Clinical Practice Guidelines. Ann Oncol. 2014; Suppl 3:iii124-37.

30. Simsa-Maziel S, Zaretsky J, Reich A, Koren Y, Shahar R, Monsonego-Ornan. IL-1R1 participates in normal growth plate development and bone modelling. American Journal of Physiology. 2013; 205E15-E21.

31. Lee YM, Fujikado N, Manaka H, Yasuda H, Iwakura Y. IL-1 plays an important role in the bone metabolism under physiological conditions. Int Immunol. 2010; 22:805-16.
32. Laurance S, Pellay FX, Dossou-Yovo OP, Verger E, Krishnamoorthy R, Lapoumeroulie C, Benecke A, Elion J. Hydroxycarbamide stimulates the production of proinflammatory cytokines by endothelial cells: relevance to sickle cell disease. Pharmacogenet Genomics. 2010; 20:257-68.

33. Rocco M, Antonelli M, Letizia V, Alampi D, Spadetta G, Passariello M, Conti G, Serio P, Gasparetto A. Lipid peroxidation, circulating cytokine and endothelin 1 levels in healthy volunteers undergoing hyperbaric oxygenation. Minerva Anestesiol. 2001; 67:393-400.

34. Nie L, Lyros O, Medda R, Jovanovic N, Schmidt JL, Otterson MF, Johnson CP, Behmaram B, Shaker R, Rafiee P. Endothelial-mesenchymal transition in normal human esophageal endothelial cells cocultured with esophageal adenocarcinoma cells: role of IL- $1 \beta$ and TGF- $\beta 2$. Am J Physiol Cell Physiol. 2014; 307:C859-77.

35. Bellamy WT, Richter L, Sirjani D, Roxas C, GlinsmannGibson B, Frutiger Y, Grogan TM, List AF. Vascular endothelial cell growth factor is an autocrine promoter of abnormal localized immature myeloid precursors and leukemia progenitor formation in myelodysplastic syndromes. Blood. 2001; 97:1427-34.

36. Ton NC, Jayson GC. Resistance to anti-VEGF agents. Curr Pharm. 2004; 10:51-64.

37. Kerbel RS. Reappraising antiangiogenic therapy for breast cancer. Breast. 2011; 20 Suppl 3:S56-60.

38. Lindahl G, Saarinen N, Abrahamsson A, Dabrosin C. Tamoxifen, flaxseed, and the lignan enterolactone increase stroma- and cancer cell-derived IL-1Ra and decrease tumor angiogenesis in estrogen-dependent breast cancer. Cancer Res. 2011; 71:51-60.

39. Pasi S, Kant R, Gupta S, Surolia A. Novel multimeric IL-1 receptor antagonist for the treatment of rheumatoid arthritis. Biomaterials. 2015; 42:121-33.

40. Dhimolea E. Canakinumab. mAbs 2010;2:3-13

41. Vendramini-Costa DB, Carvalho JE. Molecular link mechanisms between inflammation and cancer. Curr Pharm Des. 2012; 18:3831-52. 